\title{
EFSUMB Schools
}

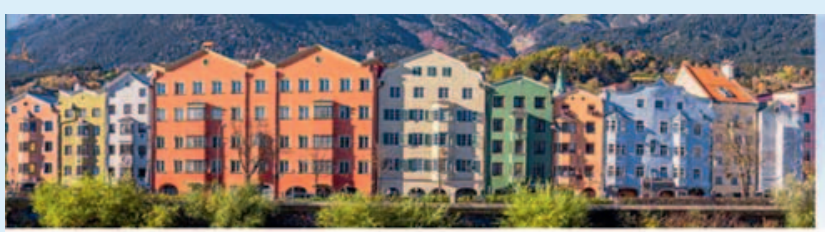

Musculoskeletal Ultrasound Course for Rheumatologists

\begin{tabular}{c} 
EUROSON SCHOOL \\
Innsbruck, Austria 26-28 May 2021 \\
EUROSON POC-US SCHOOL \\
EUROSON SCHOOL \\
Vienna, Austria > Postponed to 10-11 September, 2021 \\
\hline CME credits \\
(ECMEC's)
\end{tabular}

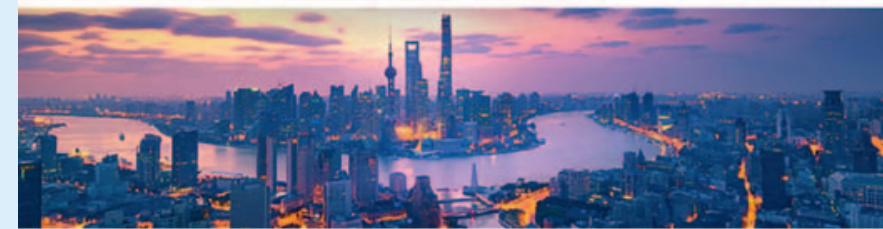

\section{EUROSON SCHOOL: Shanghai CEUS Course}

Location: Shanghai, China

July 30-31, 2021

VIEW HERE

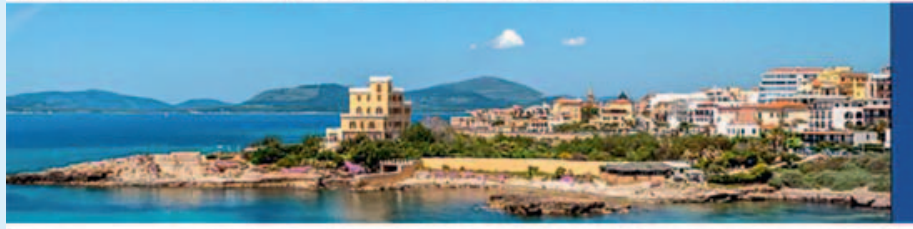

EUROSON SCHOOL: CEUS and US Elastography: standpoint 2021

Location: Alghero, Sardinia, Italy

September 3-4, 2021

VIEW HERE

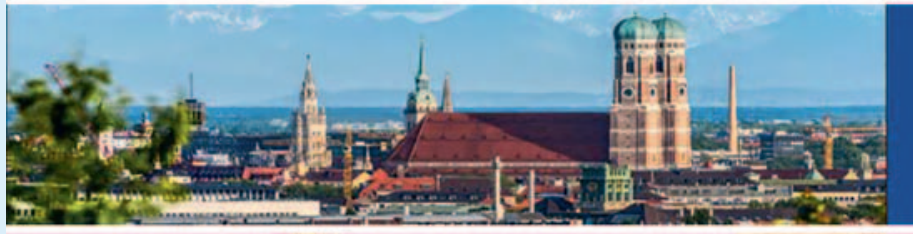

EUROSON SCHOOL: INTERNATIONAL COURSE IN CONTRAST ENHANCED ULTRASOUND, HEPATIC AND EXTRAHEPATIC INDICATIONS

Location: Munich, Germany

October 13-16, 2021

VIEW HERE

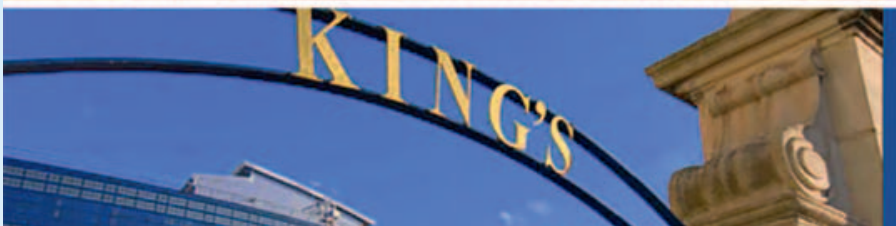

EUROSON SCHOOL: London CEUS Ultrasound Course Location: Kings College Hospital SES, London. UK

THIS MEETING IS POSTPONED TO JUNE 2022 